University of Nebraska - Lincoln

DigitalCommons@University of Nebraska - Lincoln

\title{
Biological, technical, and social aspects of applying electrified fladry for livestock protection from wolves (Canis lupus)
}

\author{
N. J. Lance \\ US Department of Agriculture
}

S. W. Breck

USDA/APHIS/WS National Wildlife Research Center, stewart.w.breck@aphis.usda.gov

C. Sime

Montana Fish, Wildlife \& Parks

P. Callahan

Wildlife Science Center

J. A. Shivik

US Department of Agriculture

Follow this and additional works at: https://digitalcommons.unl.edu/icwdm_usdanwrc

Lance, N. J.; Breck, S. W.; Sime, C.; Callahan, P.; and Shivik, J. A., "Biological, technical, and social aspects of applying electrified fladry for livestock protection from wolves (Canis lupus)" (2010). USDA National Wildlife Research Center - Staff Publications. 1259.

https://digitalcommons.unl.edu/icwdm_usdanwrc/1259

This Article is brought to you for free and open access by the U.S. Department of Agriculture: Animal and Plant Health Inspection Service at DigitalCommons@University of Nebraska - Lincoln. It has been accepted for inclusion in USDA National Wildlife Research Center - Staff Publications by an authorized administrator of DigitalCommons@University of Nebraska - Lincoln. 


\title{
Biological, technical, and social aspects of applying electrified fladry for livestock protection from wolves (Canis lupus)
}

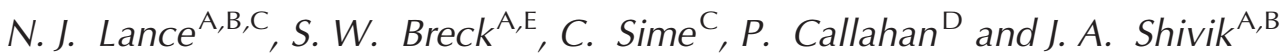 \\ A US Department of Agriculture, Wildlife Services, National Wildlife Research Center, 4101 La Porte Avenue, \\ Fort Collins, CO 80526, USA. \\ ${ }^{B}$ Department of Wildland Resources, Utah State University, 163 BNR Building, Logan, UT 84322-5295, USA. \\ CMontana Fish, Wildlife \& Parks, 1820 Meadowlark Lane, Butte, MT 59701, USA. \\ DWildlife Science Center, 5463 West Broadway, Forest Lake, MN 55025, USA. \\ ${ }^{\mathrm{E}}$ Corresponding author. Email: stewart.w.breck@aphis.usda.gov
}

\begin{abstract}
Context. Wolf predation on livestock can cause economic hardship for livestock producers as well as reduce tolerance for wolves. Lethal control of wolves is often controversial; thus, development of effective non-lethal methods for reducing wolf-livestock conflict is important. Electrified fladry is a new tool that is similar to fladry (i.e. a barrier system that scares wolves), but electrified fladry also incorporates an electric shock designed to decrease the potential for wolves to habituate to the barriers.

Aim. Evaluation of electrified fladry requires understanding of its effectiveness relative to fladry and the costs and benefits of applying it in the field.

Methods. By using captive wolves, we compared the effectiveness of electrified fladry $v$. fladry for protecting a food resource during 2-week trials. We then performed a field trial with electrified fladry for managing wolves in Montana, USA. We measured livestock depredation and wolf activity on six treatment and six control pastures, calculated the cost of installation and maintenance, and surveyed all study participants about application of electrified fladry.

Key results. We found electrified fladry 2-10 times more effective than fladry at protecting food in captivity and that hunger increased the likelihood of wolves testing fladry barriers. In field trials, we installed $14.0 \mathrm{~km}$ of EF systems in treatment pastures and detected wolves twice in control pastures but never in the treatment pastures. No livestock were killed by wolves in treatment or control pastures. A completed electrified fladry system cost $\$ 2303$ for the first km and $\$ 2032$ for each additional km, and required 31.8 person-hours per kilometre to install. We observed 18 failures (i.e. electrified system stopped working) during a total of 394 days of use. In total, $83 \%$ of ranchers who used fladry would continue to use it under certain conditions, indicating some psychological benefit to users.

Conclusions and implications. The present study has demonstrated that electrified fladry offers superior protection compared with non-electrified fladry; however, further field tests are warranted to help determine whether benefits outweigh costs.
\end{abstract}

\section{Introduction}

Wolf (Canis lupus) predation on livestock can cause economic hardship for livestock producers and lead to animosity towards wolves; however, some management actions (especially lethal control methods) have poor support from the general public (Mech 1970; Ciucci and Boitani 1998; Reiter et al. 1999; Bangs and Shivik 2001; Treves et al. 2002). Management of predation must be effective in stopping damage, and also needs to be socially acceptable; different damage-management situations may have very different contexts and it is a difficult task to identify the best lethal and non-lethal method for a particular problem (Mech 1996). Presumably, a greater variety of options would assist managers in a wider variety of complex situations. Thus, there exists a strong need for a greater number of effective management strategies that will help alleviate depredation pressure from wolves (Breck 2004; Shivik 2006).

Recent studies using the barrier technique known as fladry (flagging interspersed on a single strand of nylon twine) documented that, for short durations, captive and free-ranging wolves avoided flagging that prevented access to food (Okarma 1993; Okarma and Jedrzejewski 1997; Musiani and Visalberghi 2001; Musiani et al. 2003; Shivik et al. 2003). Fladry is a type of primary repellent in that it relies on producing a flight or startle response to deter predatory behaviour (Shivik et al. 2003; Shivik 2004). In earlier work, fladry has been rendered ineffective through the process of habituation (Musiani et al. 2003), which results in extinction of an animal's fear towards a novel object (Shivik et al. 2003). Habituation is determined by the 
intensity of a stimulus (e.g. fladry) and the motivation of individual animals (Shivik et al. 2003). A key motivational factor for many animals is hunger (e.g. Wilson et al. 1993, 1994) and it has been suggested that hunger in wolves plays an important part in the process of habituation.

Secondary repellents rely on conditioning by using aversive stimuli where flight behaviour is initiated by discomfort, pain, or a general negative experience to prevent a particular behaviour (Elliot and Covington 2001; Shivik et al. 2003; Shivik 2004). Fladry can be modified to incorporate an aversive stimulus by replacing the nylon twine that supports the flagging with an electrified wire (Gallagher Turbo-wire, North Kansas City, $\mathrm{MO})$ to create electrified fladry (EF). By combining primary and secondary repellents, EF may at first frighten, and then condition wolves to avoid the barrier, thus providing a longerlasting non-lethal tool.

Our first objective was to use controlled trials with captive wolves to compare the effectiveness of fladry to that of EF and explore whether food motivation influenced the likelihood of wolves habituating to either repellent. We hypothesised that because EF combines primary and secondary repellency, it would outperform fladry at preventing wolves from accessing a highly desirable food source. Positive results from these trials encouraged us to apply EF in the field where our objectives were to test the efficacy of $\mathrm{EF}$ on protected pastures relative to unprotected control pastures, perform a financial analysis of costs and benefits of installing and maintaining $\mathrm{EF}$, and determine the willingness of livestock owners to use EF. All work was approved by the National Wildlife Research Center's Institutional Animal Care and Use Committee QA-1332.

\section{Materials and methods}

\section{Study area}

For captive trials, we conducted controlled pen experiments during the winter 2006, by using 45 wolves in 15 packs, including 36 grey wolves (Canis lupus) in 10 packs, three Mexican grey wolves (Canis lupus baileyii) in two packs, and six red wolves (Canis rufus) in three packs. Pack sizes ranged from one to seven animals and each pack had its own enclosure at the Wildlife Science Center (WSC), Forest Lake, Minnesota. Enclosures were $105-925-\mathrm{m}^{2}$ chain-link fenced areas that contained one 19-L water bucket, one or two den boxes $\left(2-5 \mathrm{~m}^{2}\right)$ and natural vegetation, including shrubs and trees.

We conducted the field study in 2007 on private ranches that had experienced conflict with wolves in south-western and western Montana (Fig. 1). The study area of south-western Montana ('Boulder River') was located in the Boulder River valley near McLeod $\left(45^{\circ} 39^{\prime} \mathrm{N}, 110^{\circ} 06^{\prime} \mathrm{W}\right), 27 \mathrm{~km}$ south of Big Timber. The western Montana study area ('Arlee') was on the Flathead Indian Reservation near Arlee $\left(47^{\circ} 10^{\prime} \mathrm{N}, 114^{\circ} 05^{\prime} \mathrm{W}\right)$, $42 \mathrm{~km}$ north or Missoula.

At both study areas, vegetation consisted of mixed native and non-native grass pastures. Native ungulates, including whitetailed deer (Odocoileus virginianus), mule deer (Odocoileus hemionus), elk (Cervus elaphus) and moose (Alces alces), were found throughout the study areas, as were grizzly bears (Ursus arctos), black bears (Ursus americanus), mountain lions (Felis concolor), coyotes (Canis latrans) and wolves. Domestic

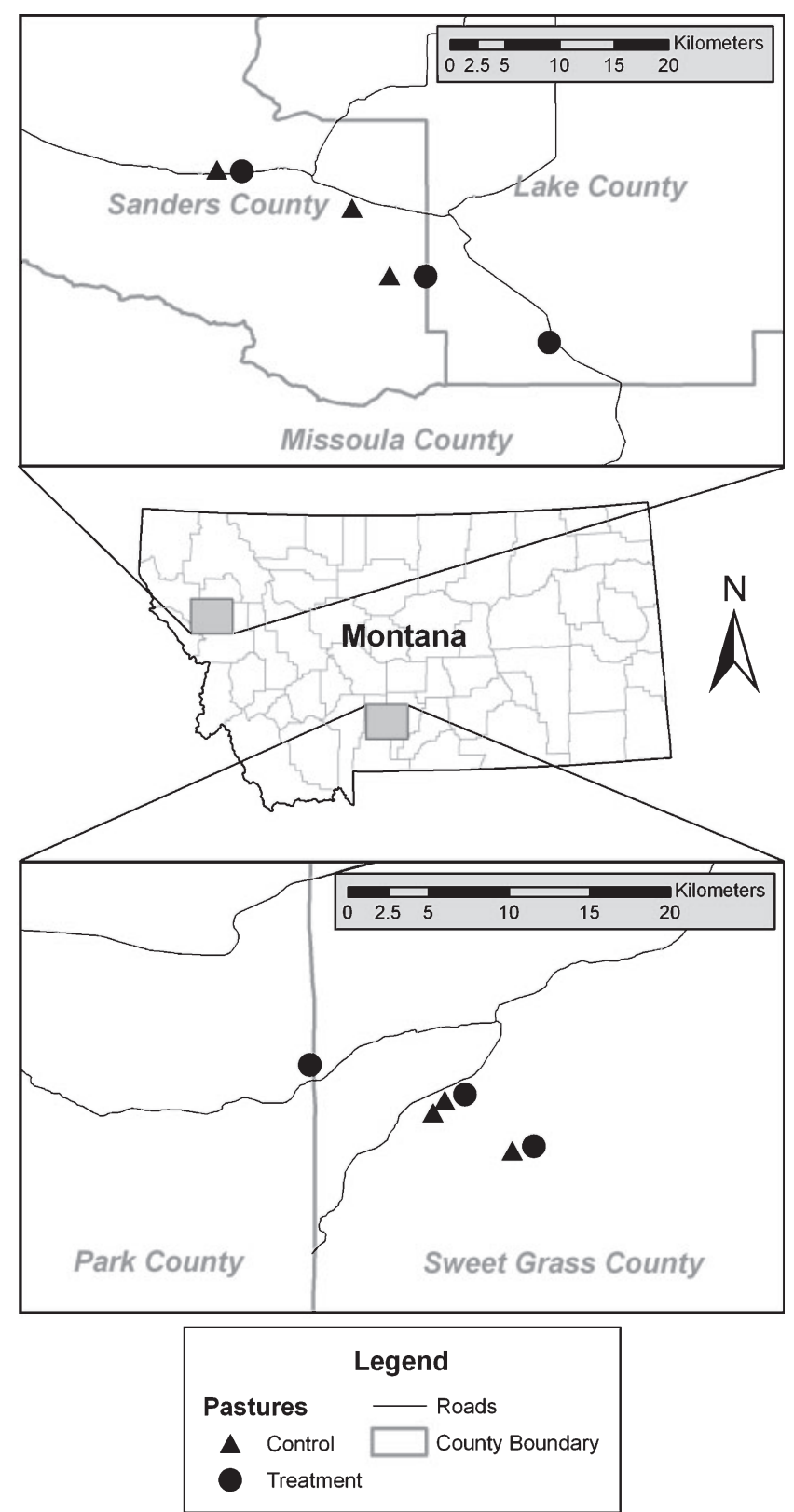

Fig. 1. Map of the study area in south-western Montana, including six treatment pastures on four ranches and combined wolf-pack ranges, and in western Montana, including six treatment pastures on five ranches.

ungulates included horses, sheep, cattle, and llamas that used a variety of pastures and open grazing areas. Wolf activity and confirmed depredations historically warranted close monitoring and at times occasional lethal removal of individuals from packs. Three wolf packs were known to use Boulder River in 2006 and two in 2007. Livestock that were confirmed killed by wolves in the Boulder River study area included four calves and nine sheep in 2007. The Arlee area had one known wolf pack in both 2006 and 2007. Livestock that were confirmed killed by wolves in the Arlee study area included seven calves and one llama in 2006 and eight calves, two cows and one llama in 2007. It is critical to note 
that the number of livestock confirmed killed by wolves is a minimum estimate and does not include animals killed but not detected or reported.

\section{Pen study}

We randomly selected five packs to receive fladry, five to receive $\mathrm{EF}$ and five to receive no barrier systems (Fig. 2). We ran trials in three phases, with each phase lasting 2 weeks. Phase 1 was a baseline treatment, where all packs received tethered carcasses and no barriers. Phase 2 had five naïve packs that received fladry treatement $(\mathrm{np} \rightarrow \mathrm{F})$, five naïve packs that received $\mathrm{EF}(\mathrm{np} \rightarrow \mathrm{EF})$ and five that were controls. Phase 3 had five packs that had received electric fladry in Phase 2 and received fladry in Phase 3 $(\mathrm{ef} \rightarrow \mathrm{F})$, five packs that had previously received fladry in Phase 2 and received electric fladry in Phase 3 ( $\mathrm{f} \rightarrow \mathrm{EF}$ ), and five controls that remained with no barriers.

For the fladry and EF treatments, we sectioned off an $18-\mathrm{m}^{2}$ area within the pen by running the barrier from one side of the pen to the other. We constructed the fladry systems protecting the food resource, following the method of Musiani and Visalberghi (2001). That is, fladry and electrified fladry systems (Carol's Creations, Arco, ID) consisted of red plastic flags $(50 \times 10 \mathrm{~cm})$ interspersed at $50-\mathrm{cm}$ intervals on a $0.2-\mathrm{cm}$-diameter blue nylon twine. We suspended the nylon twine $50 \mathrm{~cm}$ above the ground and attached it to fibreglass posts set at 3-m intervals. During the construction of the EF system, the nylon twine that typically held the flagging was replaced with a $0.2-\mathrm{cm}$ electric mixed-metal strand twine (Gallagher Turbo Wire, North Kansas, MO) of nylon and wire. We suspended the EF from the fibreglass posts in the same manner as for the fladry system. We suspended a second $0.2-\mathrm{cm}$ electric ground wire (Gallagher Turbo Wire) $13 \mathrm{~cm}$ above the ground and attached it to the fibreglass posts. A $12-\mathrm{V}$ batterypowered fence energizer (Gallagher B260) electrified the wire and produced a pulsed energy output of $\geq 2000 \mathrm{~V}$, with $2.6 \mathrm{~J}$ of stored energy and a resistance of $500 \mathrm{ohms}$. Three 1-m copper grounding rods grounded the circuit.

We mounted passive infrared motion-activated cameras (Reconyx RM30, Holmen, WI) $1.2 \mathrm{~m}$ high on the outside of the pen fence. Cameras were aimed along the barrier line and set to acquire a series of photos (four photos per second) if a wolf approached the barrier. Cameras were equipped with infrared

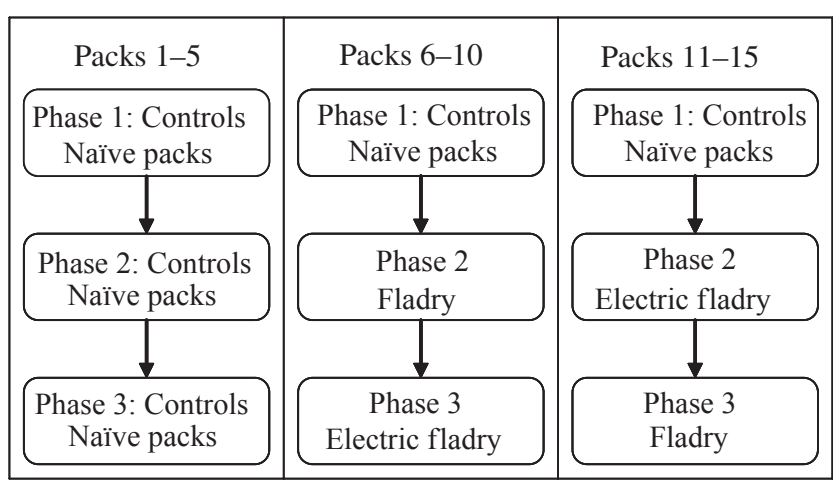

Fig. 2. Diagram of the experimental design implemented to compare wolf response to fladry with that to electrified fladry. The study was conducted on captive wolves at the Wildlife Science Center, Minnesota, USA. illumination for night-time use, so that we were able to monitor $24 \mathrm{~h}$ per day. The food resource was one eviscerated road-killed white-tailed deer (Odocoileus virginianus) previously collected in the surrounding area. Deer carcasses were the wolves' normal maintenance food. We chained deer carcasses to the corner of the pen with $1.2 \mathrm{~m}$ of $0.47-\mathrm{cm}$ stainless-steel chain to prevent carcasses from being dragged out of the corner. We maintained the Wildlife Science Center wolf-feeding protocol during the study, i.e. wolves were provided food, in the form of a deer carcass, in alternating fast and provisioning periods. At the start of the trial, we placed a deer carcass in the experimental area where it remained in the protected area for 5 days; on Days 6 and 7, we supplied carcasses in the unprotected area and replaced the old carcass in the protected area with a new one. We defined an approach as a single wolf occupying a location $\leq 2 \mathrm{~m}$ from a barrier line in a single recorded photo-data image. We show descriptively how approaches varied by treatment group (i.e. $\mathrm{np} \rightarrow \mathrm{F}, \mathrm{np} \rightarrow \mathrm{EF}, \mathrm{ef} \rightarrow \mathrm{F}, \mathrm{f} \rightarrow \mathrm{EF}$ ) relative to the number of days in the trial and the fasting regime.

We defined latency to cross as the time elapsed between the start of the trial and an event of a single wolf crossing the barrier line (measured in days) to freely feed on the protected carcass. We used the Kaplan-Meier survival estimator in program MARK (i.e. known-fate model, White and Burnham 1999) to test for differences in latency to cross the barrier. Thus, the encounter history for each pack included 14 intervals (days). We included only packs in the four primary treatments $(\mathrm{np} \rightarrow \mathrm{F}, \mathrm{np} \rightarrow \mathrm{EF}, \mathrm{ef} \rightarrow \mathrm{F}$, $\mathrm{f} \rightarrow \mathrm{EF}$ ) for this analysis because all baseline packs (i.e. Phase 1) and control packs in Phases 2 and 3 were feeding on the deer carcass within $5 \mathrm{~min}$. Because we measured latency to cross in days, inclusion of the baseline and control data would have biased results for those packs that reacted to a barrier treatment but still crossed within the first day. We tested six competing models explaining differences in the latency to cross the barrier among the four primary treatments and whether the number of wolves in each pack (PackSize) influenced the latency to cross (see Table 1). We used the small sample-size correction of AIC to select the top model (Burnham and Anderson 2002). We also calculated the mean latency to cross for each of the four primary treatment groups; for packs that never crossed, we used 14 days as part of this calculation.

\section{Field trial}

We identified six pastures on four ranches in Boulder River and six pastures on five ranches in Arlee. In each study area, we randomly assigned pastures either to control (i.e. no EF barrier) or to an EF treatment where EF was installed around the entire perimeter of the treatment pasture. The pastures (16-122 ha) contained 40-200 cows at the beginning of the calving period. When possible, we set fladry lines 1 m outside the existing barbedwire fence, away from cattle, to minimise destruction and ingestion of flags by cows. We attached fladry lines to $61-\mathrm{cm}$ fibreglass posts placed at 7.6-m intervals between t-posts set at $30.5 \mathrm{~m}$ and on corners.

We monitored pasture perimeters by using all-terrain vehicles to scan $5 \mathrm{~m}$ inside and $5 \mathrm{~m}$ outside of fladry barriers twice a week for 3 months, to determine wolf activity in or near the 12 pastures. We also checked perimeters opportunistically when weather and 
Table 1. Results of survival analysis to test for differences between the fladry treatments

$\mathrm{S}$ represents latency to cross fladry barriers, G1-G4 represent the four primary treatment groups where $\mathrm{G} 1=\mathrm{np} \rightarrow \mathrm{F}, \mathrm{G} 2=\mathrm{np} \rightarrow \mathrm{EF}$, $\mathrm{G} 3=\mathrm{ef} \rightarrow \mathrm{F}$ and $\mathrm{G} 4=\mathrm{f} \rightarrow \mathrm{EF}$ (see Materials and methods for further description of treatments); PackSize is a covariate representing the number of animals in each pack, 'v' represents differences among G1 to G4 and "= " represents equivalence between treatment groups

\begin{tabular}{|c|c|c|c|c|c|}
\hline Model & $\mathrm{AICc}$ & $\begin{array}{l}\text { Delta } \\
\text { AICc }\end{array}$ & $\begin{array}{c}\text { AICc } \\
\text { weight }\end{array}$ & $\begin{array}{c}\text { No. of } \\
\text { parameters }\end{array}$ & Deviance \\
\hline (1) $\mathrm{S}:(\mathrm{G} 1$ v G2 v G3 v G4) & 46.51 & 0.00 & 0.53 & 4 & 38.26 \\
\hline (2) S: (G1 v G2 v G3 v G4; PackSize) & 48.30 & 1.79 & 0.22 & 5 & 37.93 \\
\hline (3) $\mathrm{S}:(\mathrm{G} 1$ v G2=G3=G4) & 48.64 & 2.13 & 0.18 & 2 & 44.56 \\
\hline (4) $\mathrm{S}:(\mathrm{G} 1$ v G2 v G3= G4) & 50.53 & 4.02 & 0.07 & 3 & 44.37 \\
\hline (5) $\mathrm{S}:(\mathrm{G} 1=\mathrm{G} 3$ v G2=G4) & 66.92 & 20.42 & 0.00 & 2 & 62.85 \\
\hline (6) $\mathrm{S}$ : $(\mathrm{G} 1=\mathrm{G} 2=\mathrm{G} 3=\mathrm{G} 4)$ & 77.60 & 31.09 & 0.00 & 1 & 75.57 \\
\hline
\end{tabular}

snow conditions facilitated detection of wolf tracks. Because all nearby packs had at least one wolf radio-collared (collared previously by Montana Fish, Wildlife \& Parks or USDA-Wildlife Services), we monitored wolf presence and absence in the vicinity of ranches by scanning the valley for telemetry signals from the ground with handheld antennas and VHF radio-collars. Finally, we searched for dead or injured cattle by riding the entire pasture and conversing with ranch personnel monitoring spring calving. We recorded the number of days wolves were present in the general study areas by using telemetry, presence and absence of wolf tracks inside and outside of pastures, and the confirmed injured or dead livestock on control $v$. treatment ranches. Because of the low sample size, we present descriptive data from control and treatment areas.

\section{Cost, maintenance and social acceptance}

We calculated cost per kilometre of installing and maintaining fladry, and the mean time to install fladry per kilometre. We performed maintenance on a system only when it failed (i.e. was no longer electrified) and used these data to calculate a failure rate. We used a mail survey to measure attitudes of all participating livestock owners, concerning the application and effectiveness of EF for protecting pastures used for calving. The survey was similar for owners of protected and unprotected pastures and consisted of questions on $\mathrm{EF}$, covering applicability, effectiveness, affordability, amount of wolf sign, outcomes of the project and willingness to participate in the future. We descriptively compared survey responses of owners of protected and unprotected pastures.

\section{Results}

\section{Pen study}

During Phase 1 (i.e. baseline with no barriers), all 15 wolf packs crossed the camera line and fed on the deer carcass within $5 \mathrm{~min}$. Similarly, in both Phase 2 and 3, all five control packs crossed to the carcasses within $5 \mathrm{~min}$. In Phase 2, no trend in approach data emerged with the fladry treatment $(\mathrm{np} \rightarrow \mathrm{F})$, with all packs crossing the fladry barrier within a day. With the EF treatment $(\mathrm{np} \rightarrow \mathrm{EF})$, approaches through time decreased during the 2 -week trial and exhibited a decrease subsequent to feeding in the unprotected area on Days 6 and 7, and Days 13 and 14 (Fig. 3). In Phase 3, fladry ( $\mathrm{ef} \rightarrow \mathrm{F}$ ) and $\mathrm{EF}(\mathrm{f} \rightarrow \mathrm{EF}$ ) trials started with fewer approaches by wolves, on average, than for treatments in Phase 2
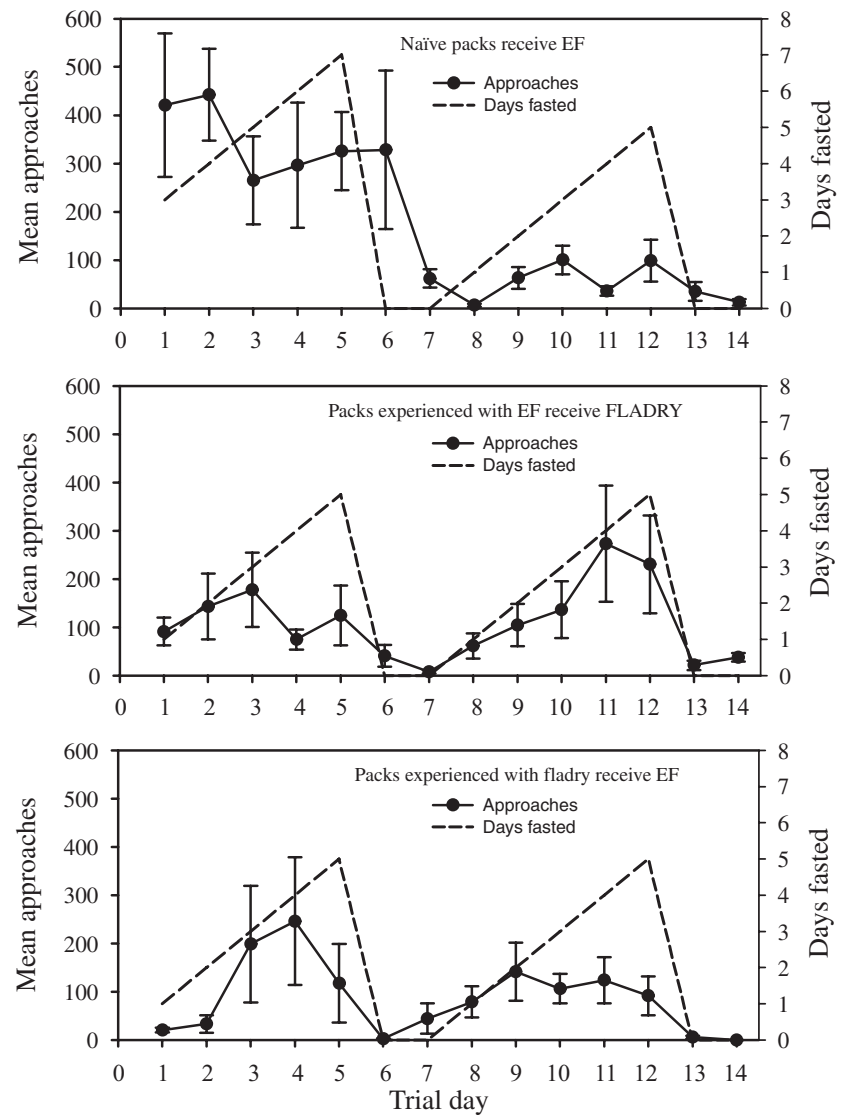

Fig. 3. Approaches $(\bar{x} \pm$ s.e. $)$ by captive wolf groups $(n=5)$ and days fasted for fladry and electrified-fladry treatments at Wildlife Science Center, Minnesota, USA.

(Fig. 3), although the wolves continued to test both treatments throughout the trial. Also in Phase 3, packs exhibited a decrease in approaches subsequent to feeding on Days 6 and 7, and Days 13 and 14 (Fig. 3).

The survival analysis showed strong support for differences in the latency to cross the barrier among all four treatment groups (i.e. top two models in Table 1 contained $75 \%$ of AICc weight) and weak support for the hypothesis that pack size influences the latency to cross the barrier (i.e. addition of the covariate PackSize to the top model decreased the AICc value for that 
model, see Models 1 and 2 in Table 1). During Phase 2, latency to cross $\mathrm{EF}(\bar{x} \pm$ s.e. $)$ was 10 times greater $(\mathrm{np} \rightarrow \mathrm{EF}$ : $10.0 \pm 2.5$ days) than that to cross fladry $(\mathrm{np} \rightarrow \mathrm{F}$ : $1.0 \pm 0.0$ days), whereas during Phase 3, latency to cross EF ( $\rightarrow$ EF: $14 \pm 0.0$ ) was nearly two times greater than that to cross fladry (ef $\rightarrow$ F: $8.2 \pm 2.7$ ) (Fig. 4).

\section{Field trials}

We detected wolves by telemetry on 11 of 20 and 19 of 29 monitoring days in the Arlee and McLeod study areas, respectively. We did not document any livestock mortality, nor did we find scat inside or outside of any protected or unprotected pastures. After combining both study areas, we detected wolves via track surveys outside of control pastures on 2 days, inside of control pastures on 2 days, outside of treatment pastures on 1 day, and never within treatment pastures.

\section{Cost, maintenance and social acceptance}

We installed $14.0 \mathrm{~km}$ of EF systems between the two study areas, and used three to eight people per pasture to install fencing. The one-time costs for a completed EF system were $\$ 2303$ for the first kilometre and \$2032 for each additional kilometre. We spent an average of 31.8 person-hours per kilometre when installing fencing. Several factors caused systems to fail, including the following: branches falling on fence; deer, elk and cattle crossing fence; and heavy snows. We observed 18 failures during a total of 394 days of use and calculated a failure rate of 0.003 failures $\mathrm{km}^{-1}$ day $^{-1}$. Mean time to locate and fix problems was $49.2 \mathrm{~min}$ (s.e. $=11.3$ ) per failure event.

All nine project participants responded to the questionnaire. For participants with a protected pasture $(n=6)$, five were willing to participate in another EF project in the future. Respondents with protected pastures primarily perceived low levels or no wolf sign before, during and after the EF were removed, both in protected pastures and near or around protected pastures. With respect to applicability and efficacy of EF, five of six respondents agreed or strongly agreed that livestock were not stressed by

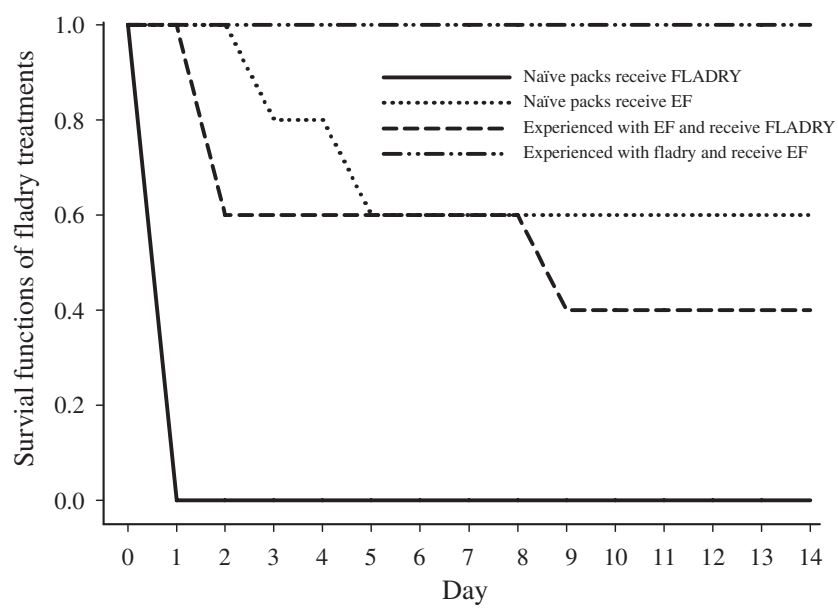

Fig. 4. Survival functions representing the latency of wolf packs to cross fladry and electrified fladry in four different treatments. Trials were performed in captivity for 2-week durations at the Wildlife Science Center, Minnesota, USA. fladry and three of six either disagreed or strongly disagreed that EF decreases the risk of depredation by wolves. But ironically, three of six also agreed or strongly agreed that because of EF, they were less concerned about livestock when livestock were not being watched. However, all six either disagreed or strongly disagreed that EF was affordable and only two of six would recommend the use of $\mathrm{EF}$ to neighbouring landowners. Furthermore, there was complete agreement that it would be unlikely that EF would be implemented if a producer incurred the total cost to apply it to any pasture size ranging from 8 to $65 \mathrm{ha}$. As the size of the pasture increased, respondents were less willing to use it. Respondents were more agreeable with using EF when there was cost sharing or no support required from producers.

For ranchers surveyed with unprotected pastures $(n=3)$, two were interested in participating in EF projects in the future and respondents varied on agreement to the applicability and potential efficacy of EF. When questioned whether EF was affordable and not too expensive, all three disagreed, moreover, all three respondents were either unlikely or very unlikely to use EF if they had to bear the total cost and labour of implementing the tool. As the size of the pasture increased, respondents were less willing to use it. However, opinions to the use of EF in the future shifted towards likely when there would be cost sharing.

\section{Discussion}

Our captive trials demonstrated that EF was superior to fladry for protecting highly desirable food items in captive situations. For both fladry and EF treatments, wolves demonstrated an initial wariness in approaches and then began to more frequently investigate the barrier during the habituation process. As wolves began biting at the flags, fladry systems failed but EF administered negative conditioning that reinforced the initial fear response. The combination of primary and secondary repellents greatly increased the efficacy of this non-lethal predation-management tool.

We also found that the number of approaches to fladry and EF barriers generally increased as fasting time increased. We suggest that increases in approaches were related to food motivation and the willingness to take more risks to obtain a resource as hunger increased, while decreases in approaches through time were explained by conditioned avoidance and decreased motivation through satiation. The implication of this result is that wolves will likely habituate to fladry faster when coupled with an increase in food motivation, thus having abundant native prey available for wolves will be critical for reducing wolf-livestock conflict.

A carryover effect of conditioned avoidance was seen in Phase 3 with the fladry treatment $(\mathrm{ef} \rightarrow \mathrm{F}$ ) where one pack did not cross for 9 days and two packs did not cross for 14 days, although eliciting guarded approaches, even with the lack of negative EF stimulus. We believe these packs were reluctant to cross the fladry barrier in Phase 3 because they still exhibited conditioned avoidance behaviours after having been exposed to EF. The cautious approaches and delayed crossing behaviours may also be explained by the lack of food motivation at the start of the trial. Response to fladry treatments in Phase 3 eventually showed an increase in mean approaches that may be explained by constant testing by wolves and the lack of negative reinforcing stimulus because the fladry was not electrified. 
Although EF proved superior to fladry in captivity, caution is needed when extrapolating the success of this tool to field settings. The following three important factors help determine whether a management tool is utilised in the field: efficacy, installation and maintenance costs, and user acceptance. Our field trial provided limited information about the efficacy of EF for excluding wolves that could be used to compare the benefits of EF to its costs. Primary evidence included detection of tracks inside an unprotected pasture on 2 days, and outside protected and unprotected pastures on 3 days, whereas we never found tracks within treatment pastures. However, our field trial did demonstrate the feasibility of installing and maintaining EF, providing strong evidence that the electrified portion of this system is durable in field conditions. Furthermore, modifying the design of EF can substantially decrease the direct and indirect costs associated with EF. Shortening the flagging to $<30 \mathrm{~cm}$ would enable EF to be placed on an existing barbed-wire fence with industry-standard hardware. In addition, it is not necessary to utilise the braided turbo wire as a ground wire; it is cheaper to utilise an industry-standard high tensile-strength electric wire, which maintains the functionality of the EF. A change of the design of EF to an integrated approach with existing fencing would decrease the number of people, supplies, installation time and difficulties with transportation and handling of equipment, thus likely improving stakeholder's willingness to use this tool.

Finally, basing the evaluation of EF only on its efficacy may erroneously discount its biological and sociological importance. In our study, five of six ranchers that used fladry would continue to use it under certain conditions, which suggest that its use provides some psychological benefit through the belief that EF has the potential to reduce risk of livestock loss and thus ease concern about livestock losses when livestock are not directly being watched by people (Lance 2009). That said, there was little interest to invest in EF as a tool. Study participants may have been reticent to invest in EF because background rates of livestock killing by wolves were generally low throughout much of the immediate and surrounding study areas, thus limiting the potential benefits of EF relative to its cost. If depredation risk was higher, it is possible that attitudes about EF or any other tool may be different. In the long term, having a tool with a higher probability of success will more likely garner social acceptance amongst users. We believe EF provides such assurances, given it is properly maintained.

\section{Recommendations and conclusions}

We believe that there is a high probability that EF is effective for excluding wolves from smaller pastures; thus, discounting the use of EF because it costs more than fladry may be a mistake. Wolfcaused livestock losses are difficult to prevent in their entirety; however, wolf-caused livestock losses have been shown to affect a recurring set of livestock owners, suggesting a spatial component to conflicts (Sime et al. 2007). Targeting application of EF to the areas prone to conflict may decrease risk and assist these disproportionately affected livestock owners.

Management of predation on livestock by wolf is an adaptive process that uses a multi-faceted approach to foster tolerance of predators, predator management and acceptable predation- management tools. Non-lethal tools are generally criticised for having short-term success and for being 'costly' when compared with lethal methods (Shivik 2004, 2006). Yet, lethal tools also have associated criticisms and costs and may not provide the most effective long-term approach when considering diverse stakeholders and when costs and benefits are defined more broadly (Phillips et al. 2004; Berger 2006). Thus, we caution against making judgments about any management tools, unless this is done with understanding of the biological, economical and sociological context of the situation and through time. Non-lethal tools such as EF may be essential for fostering and increasing tolerance of predators, especially when used in combination with other lethal and non-lethal tools (Sime et al. 2008). Under the terms of some compensation programs, the use of non-lethal tools may also be a pre-condition for reimbursement. Where wolves and livestock overlap, a suite of field-based management tools and social equity considerations, such as cost sharing of nonlethal tools, are required to facilitate wolf conservation over the long term.

\section{Acknowledgements}

Funding was provided by the USDA-Wildlife Services-National Wildlife Research Center, Montana Fish, Wildlife \& Parks, USDA-Natural Resource Conservation Service and the Animal Welfare Institute. Logistical support was provided by USDA-WS-Montana Program, Montana Fish, Wildlife \& Parks and the Confederated Salish and Kootenai Tribes of the Flathead Reservation. We thank S. Durham and M. Lewis for their valuable statistical and survey-design expertise, J. Fischer for help with GIS, and K. Malsom, M. Row, M. Buckman, J. Cade and B. Ebson for long hours and patience during daunting captures. In addition, we thank S. Courville for help with landowner relations, F. Provenza and two anonymous reviewers for input on earlier drafts, and many volunteers for help in the field.

\section{References}

Bangs, E. E., and Shivik, J. (2001). Managing wolf conflict with livestock in the northwestern United States. Carnivore Damage Prevention News $\mathbf{3}$, $2-5$.

Berger, K. M. (2006). Carnivore-livestock conflicts: effects of subsidized predator control and economic correlates on the sheep industry. Conservation Biology 20, 751-761. doi:10.1111/j.1523-1739.2006. 00336.x

Breck, S. W. (2004). Minimizing carnivore-livestock conflict: the importance and process of research in the search for optimal solutions. In 'Predators and People: From Conflict to Conservation'. (Eds N. A. Fascione, A. Delach and M. E. Smith.) pp. 13-27. (Island Press: Washington, DC.)

Burnham, K. P., and Anderson, D. R. (2002). 'Model Selection and Multimodel Inference: A Practical Information-Theoretic Approach.' 2nd edn. (Springer: New York.)

Ciucci, P., and Boitani, L. (1998). Wolf and dog depredation on livestock in central Italy. Wildlife Society Bulletin 26, 504-514.

Elliot, A. J., and Covington, M. V. (2001). Approach and avoidance motivation. Educational Psychology Review 13, 73-92. doi:10.1023/ A:1009009018235

Lance, N. J. (2009). Application of electrified fladry to decrease risk of livestock depredation by wolves (Canis lupus). M.Sc. Thesis. Utah State University, Logan, UT.

Mech, L. D. (1970). 'The Wolf: The Ecology and Behavior of an Endangered Species.' (Doubleday/Natural History Press: Garden City, NY.)

Mech, L. D. (1996). A new era for carnivore conservation. Wildlife Society Bulletin 24, 397-401.

Musiani, M., and Visalberghi, E. (2001). Effectiveness of fladry on wolves in captivity. Wildlife Society Bulletin 29, 91-98. 
Musiani, M., Mamo, C., Boitani, L., Callaghan, C., Gates, C. C., Mattei, L., Visalberghi, E., Breck, S. W., and Volpi, G. (2003). Wolf depredation trends and the use of fladry barriers to protect livestock in western North America. Conservation Biology 17, 1538-1547. doi:10.1111/j.15231739.2003.00063.x

Okarma, H. (1993). Status and management of the wolf in Poland. Biological Conservation 66, 153-158. doi:10.1016/0006-3207(93)90001-H

Okarma, H., and Jedrzejewski, W. (1997). Livetrapping wolves with nets. Wildlife Society Bulletin 25, 78-82.

Phillips, M. K., Bangs, E. E., Mech, L. D., Kelly, B. T., and Fazio, B. B. (2004). Extermination and recovery of the red wolf and grey wolf in the continuous United States. In 'Biology and Conservation of Wild Canids'. (Eds D. W. MacDonald and C. Sillero-Zubiri.) pp. 297-309. (Oxford University Press: New York.)

Reiter, D. K., Brunson, W., and Schmidt, R. H. (1999). Public attitudes toward wildlife damage management and policy. Wildlife Society Bulletin 27, 746-758.

Shivik, J. A. (2004). Non-lethal alternatives for predation management. Sheep and Goat Research Journal 19, 64-71.

Shivik, J. A. (2006). Tools for the edge: what's new for conserving carnivores. Bioscience 56, 253-259. doi:10.1641/0006-3568(2006)056[0253: TFTEWN]2.0.CO;2

Shivik, J. A., Treves, A., and Callahan, P. (2003). Nonlethal techniques for managing predation: primary and secondary repellents. Conservation Biology 17, 1531-1537. doi:10.1111/j.1523-1739.2003.00062.x
Sime, C. A., Bangs, E. E., Bradley, L., Steuber, J. E., Glazier, K., Hoover, P. J., Asher, V., Laudon, K., Ross, M., and Trapp, J. (2007). Gray wolves and livestock in Montana: a recent history of damage management: 1987-2006. In 'Proceedings of the 12th Wildlife Damage Management Conference'. (Eds D. L. Nolte, W. M. Arjo and D. H. Stalman.) pp. 16-35. (USDA-WS-National Wildlife Research Center: Fort Collins, CO.)

Sime, C. A., Asher, V., Bradley, L., Laudon, K., Ross, M., Trapp, J., Atkinson, M., and Steuber, J. E. (2008). Montana gray wolf conservation and management 2007 annual report. Montana Fish, Wildlife \& Parks, Helena, MT.

Treves, A., Jurewicz, R. R., and Naughton-Treves, L. (2002). Wolf depredation on domestic animals in Wisconsin, 1976-2000. Wildlife Society Bulletin 30, 231-241.

White, G. C., and Burnham, K. P. (1999). Program MARK: survival estimation from populations of marked animals. Bird Study 46(Suppl.), 120-139. doi:10.1080/00063659909477239

Wilson, D. S., Coleman, K., Clark, A. B., and Biederman, L. (1993). Shy bold continuum in pumpkinseed sunfish (Lepomis-Gibbosus) - an ecological study of a psychological trait. Journal of Comparative Psychology 107, 250-260. doi:10.1037/0735-7036.107.3.250

Wilson, D. S., Clark, A. B., Coleman, K., and Dearstyne, T. (1994). Shyness and boldness in humans and other animals. Trends in Ecology \& Evolution 9, 442-446. doi:10.1016/0169-5347(94)90134-1

Manuscript received 11 February 2010, accepted 3 July 2010 